\title{
Investigation of the Relationship Between IL-1Ra VNTR Variants and Psoriasis
}

\author{
๑ Aysegul Basak Akadam Teker, ๑ Burak Aksan* \\ Giresun University Faculty of Medicine, Department of Medical Genetics, Giresun, Turkey \\ *Giresun University Faculty of Medicine, Department of Dermatology, Giresun, Turkey
}

\section{Abstract}

\begin{abstract}
Aim: Psoriasis is an inflammatory skin disease characterized by hyperproliferation of keratinocytes. The imbalance between Interleukin-1 $(\mathrm{IL}-1) / \mathrm{IL}-1$ receptor antagonist (IL-1Ra) is associated with increased pro-inflammatory cytokine production and the development of inflammatory disorders. The number of repeats in the polymorphic site where IL-1Ra has an 86 bp sequential repeat sequence is of functional importance as it includes possible binding sites for transcription factors. In this context, we aimed to investigate the relationship between psoriasis and IL-1Ra VNTR in Turkish society.
\end{abstract}

Methods: One hundred twenty one patients (79 female/42 male), 250 controls (142 women/108 male) were included in the study groups and genotyped by polymerase chain reaction-restriction fragment length polymorphism method. Genotype and allele distributions were examined between the patient and control groups. The gene counting method was used to calculate the allele frequencies.

Results: The A1 allele is excessive in the control group ( $p=0.001)$. In addition, the fact that all of our patients with psoriasis area and severity index $<=10$ were carriers of the $\mathrm{A} 1$ allele.

Conclusion: The A1 allele may have a protective effect in terms of the severity of the disease and the determination of IL-1 variants may be a guide in determining the treatment protocols of these patients.

Keywords: Interleukin-1, interleukin 1 receptor antagonist, single nucleotide polymorphism, psoriasis

\section{Introduction}

Psoriasis is an inflammatory skin disease that affects the skin, joints and tendons, characterized by keratinocyte hyperproliferation caused by T-cell mediated genetic with environmental factors (1-3). Although the altered production of inflammatory markers is assumed to play a key role in pathogenesis, the true scenario of psoriasis etiology is still unknown (4). The severity and progression of the disease vary in different patients. In different studies attending that these individual differences may arise from genetic susceptibility (5). Currently, more than 40 independent loci may play a predisposition role in psoriasis. Interleukin-1 receptor antagonist (IL-1Ra), an anti-inflammatory cytokine and is a member of IL-1 containing three related genes (IL-1 $\alpha, \mathrm{IL}-1 \beta$ and IL-1RN) within a region of $430 \mathrm{~kb}$ on chromosome $2 q 14$ (6). IL-
1 Ra which is binding to the IL-1 receptor and competitively blocks the effects of $\mathrm{IL}-1 \alpha$ and $\mathrm{IL}-1 \beta$. An imbalance between IL-1 and IL-1Ra is caused to the increasing proinflammatory cytokine production and the development of inflammatory disorders. The IL-1 Ra gene has a penta-allelic polymorphic region which is containing variable numbers of a sequential repeat sequence of $86 \mathrm{bp}$ in intron two (7). The number of repeats in the polymorphic area can can be important because of repeating sequence contains possible binding sites for transcription factors. There are various conflicting data according to the functional effect of these polymorphisms on IL-1 $\alpha$ production. According to in vitro studies, the IL-1Ra A2 allele has been associated with increased IL-1Ra production in normal monocytes (8).

Several studies in various diseases including psoriasis, have shown a significant increase in the frequency of

Address for Correspondence: Aysegul Basak Akadam Teker, Giresun University Faculty of Medicine, Department of Medical Genetics, Giresun, Turkey Phone: +90 5332703564 E-mail: aba2904@hotmail.com ORCID: orcid.org/0000-0003-3618-0560 Received: 18.11.2020 Accepted: 15.02.2021 
IL-1Ra A2 (9). IL-1Ra deficient mice have shown similar histological findings in human psoriasis $(10,11)$. In addition, it has been reported increased IL-1Ra mRNA levels in cell cultures obtained from psoriasis patients and with this information relationship between the IL-1 gene complex and psoriasis is getting important so the researchers have focused their attention on the variations in this complex (12). Polymorphisms in IL-1 gene complex are of considerable interest as they are thought to affect levels of IL-1 secretion.

However, studies which are investigating the relationship between IL-1Ra variable number of sequential repeats (VNTR) and psoriasis are quite limited and their results are conflicting. We aimed to investigate the relationship between psoriasis and IL-1Ra VNTR in Turkish population in this study.

\section{Methods}

\section{Study Design}

The present study protocol was approved by the Ethics Committee of the Giresun University Faculty of Medicine (number: KAEK-115) and written informed consents were obtained from all patients. All procedures performed in this study were in compliance with the ethical standards of the institutional and/or national research committee and the Declaration of Helsinki (13). In this study, 121 psoriasis patients who applied to Giresun University. Ilhan Ozdemir Training and Research Hospital between 20192020, diagnosed clinically or histopathologically, were included in our study group. As the control group, 250 individuals who applied to the dermatology outpatient clinic with a dermatological disease and were age-matched were included in the study group. These individuals had no history of psoriasis or any chronic inflammatory disease. The demographic and clinical characteristics of both psoriasis patients and the control group were recorded in synchronized Excel files for later use. Psoriatic arthritis was investigated in all patients. Children (age $<18)(n=5)$, pregnant and lactating participants $(n=2)$, and participants ( $n=10)$ with a history of any immunological or inflammatory disease were excluded from the study.

\section{Interleukin-1 Receptor Antagonist Genotype Analysis}

We isolated genomic DNA from the leukocytes using Roche isolation kit (Roche high pure isolation kit, Germany). The extracted DNA was maintained at $4{ }^{\circ} \mathrm{C}$ until analysis. The VNTR mutation in the IL-1Ra gene was determined by polymerase chain reaction (PCR). The PCR product was generated by the use of oligonukleotid F: 5 "-CTCAGCAACACTCCTAT-3" R: 5 "-TCCTGGTCTGCAGGTAA-3". PCR protocol for the polymorphic region within intron 2 of the IL-1Ra gene with a VNTR of $86 \mathrm{bp}$; initial denaturation at $95{ }^{\circ} \mathrm{C}$ for $5 \mathrm{~min}$, followed by 35 cycles of $95{ }^{\circ} \mathrm{C}$ for $45 \mathrm{~s}, 55{ }^{\circ} \mathrm{C}$ for $45 \mathrm{~s}$ and $72{ }^{\circ} \mathrm{C}$ for $45 \mathrm{~s}$ before terminal elongation at $72{ }^{\circ} \mathrm{C}$ for $10 \mathrm{~min}$. The obtained PCR products were genotyped by imaging under UV in a $2 \%$ agarose gel and five alleles were characterized according to the number of repeats (14). Allele 1 (four repeats) was $410 \mathrm{bp}$, allele 2 (two repeats) $240 \mathrm{bp}$, allele 3 (five repeats) 500 bp, allele 4 (three repeats) was 325 bp, and allele 5 (six repeats) was 595 bp.

\section{Statistical Analysis}

The statistical analysis of this study was made using the SPSS 20 package program. Statistical significance was taken as $p<0.05$. Alleles and genotype frequencies were calculated by direct counting. The chi-square $\left(\chi^{2}\right)$ test was used to evaluate the intergroup differences in the frequency of genotype and alleles. Odds ratio (OR) and $95 \%$ confidence interval $(95 \% \mathrm{Cl})$ are given to determine the risk factor between groups.

\section{Results}

The demographic characteristics of the study groups are given in Table 1. The patients were divided into two groups according to the age of onset of psoriasis $[<=40$ : early onset $(n=78)$; $>40$ : late onset $(n=43)]$. Among our patients, 92 people had no psoriatic arthritis, while 29 suffered from psoriatic arthritis. In addition, 101 patients did not have a family history of psoriasis, while 20 patients had a history of psoriasis in their first-degree relatives.

In the patient and control groups included in the study, only 3 alleles $[A 1=410$ (four replicates), $A 2=242$ (two replicates), $A 3=500$ (five replicates)] were observed (Table

\begin{tabular}{|c|c|c|c|c|}
\hline & & $\begin{array}{l}\text { Cases } \\
(n=121)\end{array}$ & $\begin{array}{l}\text { Controls } \\
(n=250)\end{array}$ & p \\
\hline Age (Years) & (Mean \pm SD) & $44.08 \pm 14.17$ & $47.61 \pm 12.0$ & NS \\
\hline \multicolumn{5}{|l|}{$\operatorname{Sex} n(\%)$} \\
\hline $\begin{array}{l}\text { Male } \\
\text { Female }\end{array}$ & - & $\begin{array}{l}42(34.7 \%) \\
79(65.3 \%) \\
\end{array}$ & $\begin{array}{l}108(43.2 \%) \\
142(56.8 \%) \\
\end{array}$ & NS \\
\hline \multicolumn{5}{|l|}{ Artrit n (\%) } \\
\hline $\begin{array}{l}\text { Artrit + } \\
\text { Artrit - }\end{array}$ & - & $\begin{array}{l}29(24.0 \%) \\
92(76.0 \%)\end{array}$ & - & - \\
\hline $\begin{array}{l}\text { Age of onset } \\
\mathrm{n}(\%)\end{array}$ & $\begin{array}{l}<=40 \\
>40\end{array}$ & $\begin{array}{l}78(65.0 \%) \\
43(35.0 \%)\end{array}$ & - & - \\
\hline $\begin{array}{l}\text { Family history } \\
\mathrm{n}(\%)\end{array}$ & $\begin{array}{l}+ \\
-\end{array}$ & $\begin{array}{l}20(16.5 \%) \\
101(83.4 \%)\end{array}$ & - & - \\
\hline $\begin{array}{l}\text { PASI } \\
\text { n (\%) }\end{array}$ & $\begin{array}{l}>10 \\
<=10\end{array}$ & $\begin{array}{l}108(89.3 \%) \\
13(10.7 \%)\end{array}$ & - & - \\
\hline \multicolumn{5}{|c|}{$\begin{array}{l}\text { Mean values were compared between patients and controls by using } \\
\text { the Student's t-test. Qualitative data were analyzed by the chi-square } \\
\text { test. NS: Not significant, PASI: Psoriasis area and severity index, Data } \\
\text { are presented as mean } \pm \text { SD and } n(\%) \text {. Bold values were statistically } \\
\text { significant ( } p<0.05) \text {. n: Number of samples SD: Standard deviation }\end{array}$} \\
\hline
\end{tabular}


2). The frequency distribution of these alleles in Turks is similar to other world populations, A1 is the most common allele, followed by $\mathrm{A} 2$ and $\mathrm{A} 3$ are rare alleles. There was a statistically significant difference in genotype and allele frequencies between patients and controls $(p<0.001)$. The IL-Ra VNTR allele and genotype frequencies in psoriasis patients and controls are shown in Table 2. The A1 allele was present at a significantly higher frequency in the control group ( $p=0.001$, OR: $0.322 \% 95 \mathrm{Cl}$ : 0.159-0.655). In addition, interestingly, all of our patients with Psoriasis area and severity index (PASI) $<=10$ are carriers of the $A 1$ allele (data not shown). The $\mathrm{A} 2$ and $\mathrm{A} 3$ allele did not show a significant difference between the two groups $(p=0.363$; $p=0.560$, respectively).

\section{Discussion}

Two important studies in 2014 and 2019 highlighted the importance of the IL-1 $\beta$-IL-1R signaling pathway in psoriasis. In one of these studies Lowes et al. (3) showed IL-1 $\beta$-IL-1R signaling pathway plays critical roles in psoriasis pathogenesis and in the other Cai et al. (15) data showed that the IL-1 $\beta-I L-1 R$ signaling pathway is associated with disease progression and treatment response. The results of these two studies suggest that this pathway not only a target for the treatment of the disease, it also for a an important target in disease progression and response of treatment.

Di Paolo et al. (16) demonstrated the effects of IL1 Ra on blocking IL-1 $\alpha$ and IL-1 $\beta$ activity. In addition, IL1 Ra knockout mice developed skin inflammation with histopathological characteristics similar to human psoriasis (17), while positive effects were observed in individuals with psoriasis treated with recombinant IL-1Ra (18). The significantly higher mRNA expressions of IL-1 receptor antagonists evaluated in peripheral blood mononuclear cells (PBMCs) of 10 psoriatic patients and six healthy controls in psoriasis patients also a documentation of the relationship between the IL-1 family and psoriasis (12). When this information is evaluated and the role of IL$1 \mathrm{Ra}$ in controlling inflammation is considered, it can be assumed that the variations in this gene may contribute to the pathogenesis of psoriasis by affecting gene expression levels. Studies showing that the IL-1Ra VNTR A2 allele is associated with a variety of epithelial-related chronic inflammatory diseases, including alopecia areata, lichen sclerosis, systemic lupus erythematosus, ulcerative colitis and scleroderma $(19,20)$. A few studies which are investigating the relationship between psoriasis and IL$1 \mathrm{Ra}$, are very limited and contain conflicting results.

One of study from the G.Britain by Tarlow et al. (9) showed that the frequency of the $A 2$ allele increased in the early-onset ( $<40$ years) cohort with psoriasis and decreased significantly in the late-onset ( $>40$ years) cohort compared to controls, and on the other hand Moorchung et al. (21) reported that there is no relationship between VNTR and psoriasis.

In addition; other studies from Egypt, Taiwan, and Canada showed that there was no significant difference in the frequencies of all genotypes and alleles related to the IL-1Ra VNTR polymorphism (22-24). Finally, a meta analysis result emphasized that there is no relationship between IL-1Ra and Psoriasis pathogenesis (25).

In the results of our study, the A1 allele was found to be statistically significantly higher in the control group compared to the patient group. This suggests that the A1 allele may have a protective effect against the severity of the disease. In addition, the fact that all of our patients with PASI $<=10$ were carriers of the $A 1$ allele also supports this finding. $A 2$ and $A 3$ alleles did not show statistically significant differences in patient and control groups, consistent with the studies from Egypt, Taiwan, and Canada.

\begin{tabular}{|c|c|c|c|c|c|c|c|c|}
\hline \multicolumn{9}{|l|}{ Genotip } \\
\hline & \multicolumn{2}{|l|}{ A1/A1 } & A1/A2 & \multicolumn{2}{|l|}{ A1/A3 } & \multicolumn{2}{|l|}{ A2/A2 } & A3/A3 \\
\hline Cases $n(\%)(n=121)$ & \multicolumn{2}{|c|}{50 (41.3\%) } & $42(34.7 \%)$ & \multicolumn{2}{|c|}{$7(5.8 \%)$} & \multicolumn{2}{|c|}{$10(8.3 \%)$} & $10(8.3 \%)$ \\
\hline Controls n (\%) (n=250) & \multicolumn{2}{|c|}{117 (46.8\%) } & $109(43.6 \%)$ & \multicolumn{2}{|c|}{$11(4.4 \%)$} & \multicolumn{2}{|c|}{$13(5.2 \%)$} & $0(0.0 \%)$ \\
\hline$p$ & \multicolumn{8}{|c|}{$<0.001^{*}$} \\
\hline \multicolumn{9}{|l|}{ Allele } \\
\hline & A1 (+) & A1 (-) & $\mathrm{A} 2(+)$ & A2 (-) & A3 $(+)$ & A3 (-) & A4 $(+)$ & A5 $(+)$ \\
\hline Cases $(n=121)$ & 0.83 & 0.16 & 0.43 & 0.57 & 0.05 & 0.95 & 0.0 & 0.0 \\
\hline Controls $(n=250)$ & 0.94 & 0.06 & 0.48 & 0.52 & 0.04 & 0.96 & 0.0 & 0.0 \\
\hline$x^{2}$ & \multicolumn{2}{|l|}{10.579} & \multicolumn{2}{|l|}{0.828} & \multicolumn{2}{|l|}{0.339} & - & - \\
\hline$p$ & \multicolumn{2}{|c|}{$0.001 * *$} & \multicolumn{2}{|l|}{0.8363} & \multicolumn{2}{|l|}{0.560} & - & - \\
\hline
\end{tabular}




\section{Study Limitations}

Our study has some limitations because of IL-1Ra serum levels and expression levels could not compared. Therefore, we think that our study should be supported by new studies which have expression levels in a larger sample group.

\section{Conclusion}

Our study is the first study which was investigating psoriasis and IL-1Ra VNTR polymorphism in Turkish population. As a result; we think that the A1 allele may have a protective effect in terms of the severity of the disease and the determination of IL-1Ra variants may be a guide in determining the treatment protocols for these patients.

\section{Authorship Contributions}

Concept: A.B.A.T., Design: A.B.A.T., B.A., Data Collection or Processing: A.B.A.T., B.A., Analysis or Interpretation: A.B.A.T., B.A., Literature Search: A.B.A.T., B.A., Writing: A.B.A.T.

Conflict of Interest: No conflict of interest was declared by the authors.

Financial Disclosure: The present study was supported by a grant from the Scientific Research Projects Coordination Unit of Giresun University (project no: SAĞBAP-A-270220-07).

\section{References}

1. Naldi L. Epidemiology of psoriasis. Curr Drug Targets Inflamm Allergy 2004;3:121-8.

2. Boyman O, Conrad C, Tonel G, Gilliet M, Nestle FO. The pathogenic role of tissue-resident immune cells in psoriasis. Trends Immunol 2007;28:51-7.

3. Lowes MA, Bowcock AM, Krueger JG. Pathogenesis and therapy of psoriasis. Nature 2007;445:866-73.

4. Elder JT, Nair RP, Henseler T, et al. The genetics of psoriasis 2001: the odyssey continues. Arch Dermatol 2001;137:1447-54.

5. Enamandram M, Kimball AB. Psoriasis epidemiology: the interplay of genes and the environment. J Invest Dermatol 2013;133:287-9.

6. Bidwell J, Keen L, Gallagher G, et al. Cytokine gene polymorphism in human disease: on-line databases. Genes Immun 1999;1:3-19.

7. Mistry A, Savic S, van der Hilst JCH. Interleukin-1 Blockade: An Update on Emerging Indications. BioDrugs 2017;31:207-21.

8. Danis VA, Millington M, Hyland VJ, Grennan D. Cytokine production by normal human monocytes: inter-subject variation and relationship to an IL-1 receptor antagonist (IL1Ra) gene polymorphism. Clin Exp Immunol 1995;99:303-10.

9. Tarlow JK, Cork MJ, Clay FE, et al. Association between interleukin-1 receptor antagonist (IL-1 ra) gene polymorphism and early and late-onset psoriasis. Br J Dermatol 1997;136:147-8.
10. Nakajima A, Matsuki T, Komine $M$, et al. TNF, but not IL-6 and IL-17, is crucial for the development of T cell-independent psoriasis-like dermatitis in $111 \mathrm{rn}-/$ - mice. J Immunol 2010;185:1887-93.

11. Shepherd J, Little MC, Nicklin MJ. Psoriasis-like cutaneous inflammation in mice lacking interleukin-1 receptor antagonist. J Invest Dermatol 2004;122:665-9.

12. Kim HJ, Kim SH, Park J, Lee M, Kim DS, Lee MG. Up-regulation of receptor antagonist interleukin-1 family members in psoriasis and their regulation by pro-inflammatory cytokines. J Dermatol Sci 2016;82:204-6.

13. World Medical Association. World Medical Association Declaration of Helsinki: ethical principles for medical research involving human subjects. JAMA 2013;310:2191-4.

14. Settin A, Abdel-Hady H, El-Baz R, Saber I. Gene polymorphisms of TNF-alpha(-308), IL-10(-1082), IL-6(-174), and IL-1Ra(VNTR) related to susceptibility and severity of rheumatic heart disease. Pediatr Cardiol 2007;28:363-71.

15. Cai Y, Xue F, Quan C, et al. A Critical Role of the IL-1 $\beta$-IL$1 \mathrm{R}$ Signaling Pathway in Skin Inflammation and Psoriasis Pathogenesis. J Invest Dermatol 2019;139:146-56.

16. Di Paolo NC, Shayakhmetov DM. Interleukin $1 \alpha$ and the inflammatory process. Nat Immunol 2016;17:906-13.

17. Nakajima A, Matsuki T, Komine $M$, et al. TNF, but not IL-6 and IL-17, is crucial for the development of T cell-independent psoriasis-like dermatitis in $111 \mathrm{rn}-/$ - mice. J Immunol 2010;185:1887-93

18. Viguier M, Guigue P, Pagès C, Smahi A, Bachelez H. Successful treatment of generalized pustular psoriasis with the interleukin-1-receptor antagonist Anakinra: lack of correlation with IL1RN mutations. Ann Intern Med 2010;153:66-7.

19. Clay FE, Cork MJ, Tarlow JK, et al. Interleukin 1 receptor antagonist gene polymorphism association with lichen sclerosus. Hum Genet 1994;94:407-10.

20. Mansfield JC, Holden H, Tarlow JK, et al. Novel genetic association between ulcerative colitis and the antiinflammatory cytokine interleukin-1 receptor antagonist. Gastroenterology 1994;106:637-42.

21. Moorchung N, Vasudevan B, Chatterjee M, Mani NS, Grewal RS. Interleukin-1 Gene Polymorphisms and their Relation with NFkB Expression and Histopathological Features in Psoriasis. Indian J Dermatol 2015;60:432-8.

22. Chang YT, Chou CT, Yu CW, et al. Cytokine gene polymorphisms in Chinese patients with psoriasis. $\mathrm{Br} \mathrm{J}$ Dermatol 2007;156:899-905.

23. Peddle L, Butt C, Snelgrove T, Rahman P. Interleukin (IL) 1alpha, IL1beta, IL receptor antagonist, and IL10 polymorphisms in psoriatic arthritis. Ann Rheum Dis 2005;64:1093-4.

24. Settin AA, Hassan HA, El-Baz RA, Hassan TA. Association of cytokine gene polymorphisms with psoriasis in cases from the nile delta of egypt. Indian J Dermatol 2011;56:272-7.

25. Qiao J, Jia QN, Jin HZ. Lack of association of the IL-1RN and IL-10 polymorphisms with risk of psoriasis: A meta-analysis. Mol Genet Genomic Med 2019;7:00512. 